\title{
Experimental Results Applying Second Order Sliding Mode Control to a PEM Fuel Cell Based System th
}

\author{
Cristian Kunusch ${ }^{\mathrm{a}, *}$, Paul F. Puleston ${ }^{\mathrm{b}}$, Miguel A. Mayosky ${ }^{\mathrm{b}}$, Leonid Fridman ${ }^{\mathrm{c}}$ \\ ${ }^{a}$ Institut de Robòtica i Informàtica Industrial (CSIC-UPC), Parc Tecnològic de Barcelona, c/ Llorens i Artigas 4-6, 08028 Barcelona, Spain. \\ ${ }^{b}$ Laboratorio de Electrónica Industrial Control e Instrumentación, Facultad de Ingeniería, UNLP, B1900TAG La Plata, Argentina. \\ ${ }^{c}$ Departamento de Ingeniería de Control y Robótica, Facultad de Ingeniería UNAM, Edificio T, Ciudad Universitaria D.F., Mexico.
}

\begin{abstract}
A robust control solution is proposed to solve the air supply control problem in autonomous polymer electrolyte membrane fuel cells (PEMFC) based systems. A Super Twisting controller is designed using a nonlinear model of a laboratory fuel cell test station, even a Lyapunov based stability discussion is included. Subsequently, the proposed control strategy is successfully implemented in the laboratory test bench. Highly satisfactory results are obtained, regarding dynamic behaviour, oxygen stoichiometry regulation and robustness against uncertainty.
\end{abstract}

Keywords: PEM fuel cell systems, second order sliding mode control, experimental results.

\section{Introduction}

Increasing society concerns regarding the fundamental problems of the use of hydrocarbons are soaring research on renewable power sources (Barbir, 2005). Hydrogen, which is an efficient and clean energy carrier, is a viable solution to mitigate the problems associated to greenhouse gas emissions and source dependence. In future energy schemes, renewable energy sources will be fundamental and hydrogen can play a key role for efficiency enhancement. Considering that renewable energy sources are often intermittent and difficult to predict, it is usually difficult to match the energy production and the energy demand. Thus, the introduction of hydrogen as an energy vector helps this matching and allows increasing the efficiency and stability of the generation systems. Going from a hydrocarbon based energy system to a new scheme where hydrogen plays a basic role, naturally introduces fuel cells (FC) in the energy conversion chain. These devices produce electrical power through the catalytic reaction of hydrogen oxidation, they are highly efficient and their only by-products are water and heat. However, high costs, low reliability and short lifetime of fuel cells are still limiting its massive utilization in real applications. In this context, not only the improvement of the system design, better materials and components, but also new advanced control systems, are necessary to achieve costs reduction, faster dynamic responses, longer lifetimes and the optimization of the energy conversion.

\footnotetext{
A shorter version of this paper was presented at the 11th International Workshop on Variable Structure Systems, National Autonomous University of Mexico, June 26-28, 2010.

*Corresponding author: Te: +34 93 4015786, Fax: +34 934015750

Email addresses: ckunusch@iri.upc.edu (Cristian Kunusch), puleston@ing.unlp.edu.ar (Paul F. Puleston), mayosky@ieee.org (Miguel A. Mayosky), lfridman@servidor. unam.mx (Leonid Fridman)
}

Improving the dynamic response and efficiency of a fuel cell based system is a challenging control goal, as the FC itself involves the interaction of many nonlinear components. For instance, a system comprising an air supply subsystem of a polymer electrolyte membrane (PEM) fuel cell stack connected to an air compressor is described by a seventh order nonlinear model (Kunusch et al., 2011), where many internal variables are inaccessible for its use in control algorithms. Besides, there are measurable and non-measurable disturbances that strongly affect system operation, as well as model uncertainties.

Then, reliable control systems ensuring stability and performance, as well as robustness to model uncertainties and external perturbations are of capital importance for PEMFC success. In particular, the oxygen stoichiometry control system (Pukrushpan et al., 2004)(Larminie and Dicks, 2003)(Gruber et al., 2012), has to be able to optimise the system conversion efficiency, avoiding performance deterioration together with eventual irreversible damages in the polymeric membranes, due to oxygen starvation. As a novel solution to this technological problem, an air flow nonlinear control design and its implementation in a laboratory fuel cell system are presented in this work. In the current work, the control problem is solved through a Super Twisting algorithm (STA). Among some of the advantages of the control solution, it can be highlighted the capability of system robust stabilization, finite time convergence to the sliding surface and chattering reduction even in the presence of model uncertainties and disturbances (Levant, 1993).

The potentiality of this design technique applied to fuel cells has been preliminary explored in (Kunusch et al., 2009), using a well known model of the PEMFC system for automotive applications presented in (Pukrushpan et al., 2004). While in recent years important and sound works have also been published. In (Talj et al., 2010) it is applied a SOSM control in a cascade configuration to regulate the oxygen flow of a $33 \mathrm{~kW}$ 
fuel cell stack. This article presents the regulation of the compressor speed trough a Super Twisting controller and then the air mass flow regulation is achieved based on the compressor static characteristic. In this work, an order reduction and transformation of the system model is performed to design the controllers, even experimental tests in nominal operation are presented. In (García-Gabin et al., 2010) a comprehensive study of sliding mode implementation in PEM fuel cells is addressed. This work considers a commercial $1.2 \mathrm{~kW}$ stack and the control development is performed using a first order sliding method, while the design is based on a linear model of the plant and considering an integral-differential sliding surface. The control law also incorporates a feedforward term in order to compensate the stack current effects and enhance the controller dynamic performance. In (Matraji et al., 2010), initial simulation results are presented to control a MIMO PEM fuel cell plant using the so-called Twisting algorithm and the model derived in (Pukrushpan et al., 2004).

The controller design presented in the current paper is based on the complete nonlinear model of the plant (seventh order), while the control solution directly tackles the oxygen supply through a STA. In this way, avoiding model reduction and cascade control, the controller presents enhanced robustness properties and a more direct path between design and implementation. Moreover, a Lyapunov based stability and reaching time analysis is provided. Finally, simulation results show the suitability of STA to address the control problem, while its successful implementation in an actual fuel cell based generation system experimentally demonstrates the viability of this control solution, even under external disturbances.

\section{Experimental PEM fuel cell system}

Details of the laboratory test station used for controller development and testing are shown in Figure 1. A schematic diagram of the system is depicted in Figure 2, where sensors and actuators are also displayed. The main subsystems are:

- Air Compressor: 12V DC oil-free diaphragm vacuum pump. Input voltage to this device is used as the main control action.

- Hydrogen and Oxygen humidifiers and line heaters: These are used to maintain proper humidity and temperature conditions inside the cell stack, an important issue for PEM membranes. Cellkraft ${ }^{\circledR}$ membrane exchange humidifiers are used in the current set-up. Decentralized PID controllers ensure adequate operation values.

- Fuel cell stack: an ElectroChem ${ }^{\circledR} 7$-cell stack with Nafion $115^{\circledR}$ membrane electrodes assemblies (MEAs) is used, with a catalyst loading of $1 \mathrm{mg} / \mathrm{cm}^{2}$ of platinum, $50 \mathrm{~cm}^{2}$ of active area and $100 \mathrm{~W}$ power.

Different sensors are incorporated to measure specific variables, suited for modelling and control. Regarding Figure 2, these are: motor shaft angular velocity $\left(\omega_{c p}\right)$, compressor air

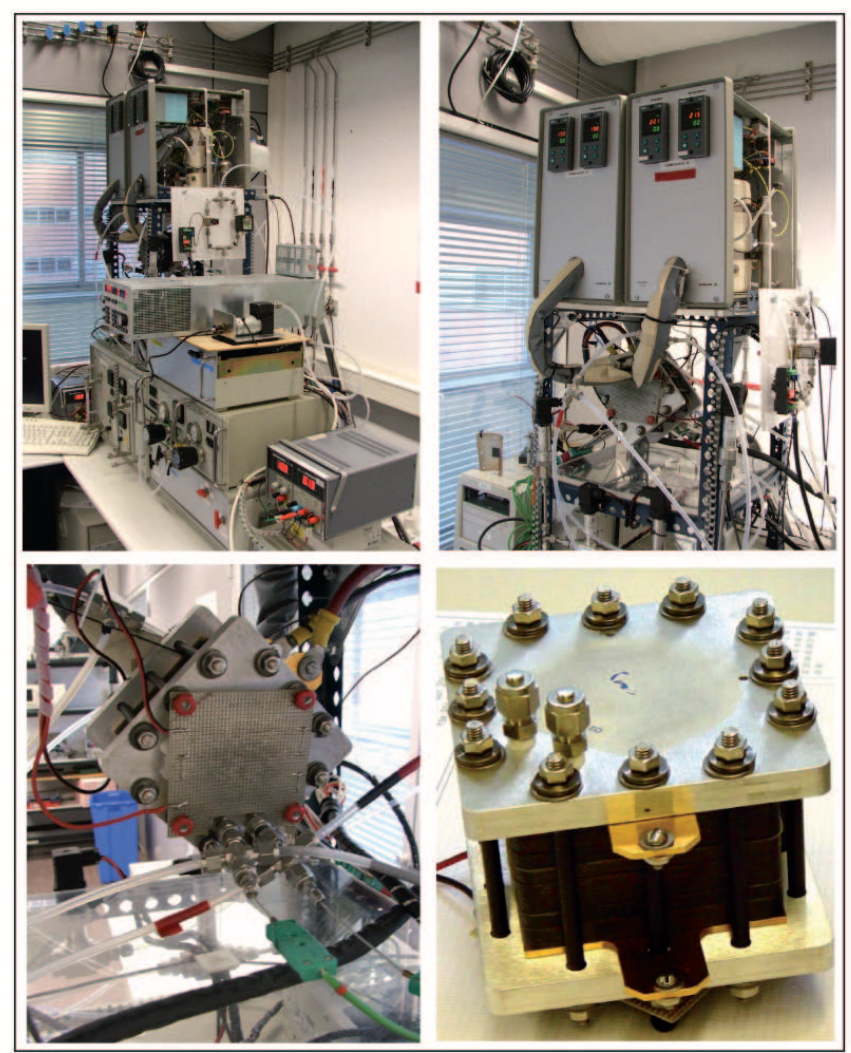

Figure 1: Experimental PEM fuel cells laboratory at IRI (UPC-CSIC)

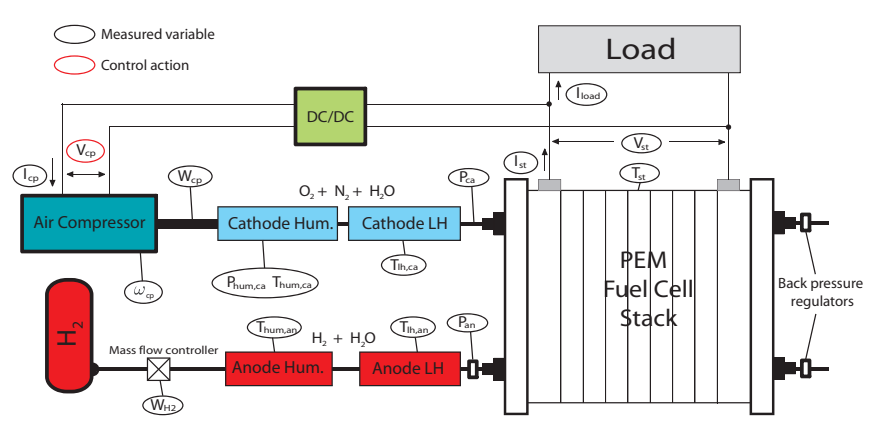

Figure 2: PEM Fuel cell system schematics

mass flow $\left(W_{c p}\right)$, hydrogen mass flow $\left(W_{H 2}\right)$, cathode and anode humidifiers pressures $\left(P_{\text {hum,ca }}\right.$ and $\left.P_{\text {hum,an }}\right)$, stack pressure drops $\left(P_{c a}\right.$ and $\left.P_{a n}\right)$, motor stator current $\left(I_{c p}\right)$ and voltage $\left(V_{c p}\right)$, stack voltage $\left(V_{s t}\right)$ and load current $\left(I_{\text {load }}\right)$. Besides, a number of sensors were included to register significant temperatures $\left(T_{s t}\right.$, $T_{\text {hum,ca }}, T_{l h, c a}, T_{h u m, a n}$ and $\left.T_{l h, a n}\right)$. It must be noted that in a typical fuel cell application many of these measurements are not necessary. For instance, the controller proposed in section 5 only requires measurement of the stack current and the compressor air flow.

System modelling was performed by the authors combining theoretical techniques and empirical analysis. Dynamic models of the compressor, cathode and anode humidifier, line heaters, 
fuel cell stack channels and membrane water transport were developed and experimentally validated. The resulting model, suitable for SOSM control design, has the following general form:

$$
\dot{x}=F(x(t))+G \cdot u(t)
$$

where $X_{1}=\left[\begin{array}{lllllll}x_{1} & x_{2} & x_{3} & x_{4} & x_{5} & x_{6} & x_{7}\end{array}\right] \in \mathcal{R}^{7}, u \in \mathcal{R}$ and $G$ is a constant.

- $x_{1}=\omega_{c p}$ : compressor shaft speed $[\mathrm{rad} / \mathrm{s}]$.

- $x_{2}=m_{\text {hum,ca }}$ : mass of air in the cathode humidifier $[\mathrm{kg}]$.

- $x_{3}=m_{o_{2}, c a}$ : mass of oxygen in the stack cathode $[\mathrm{kg}]$.

- $x_{4}=m_{N_{2}, c a}$ : mass of nitrogen in the stack cathode [kg].

- $x_{5}=m_{v_{2}, c a}$ : mass of vapour in the stack cathode $[\mathrm{kg}]$.

- $x_{6}=m_{H_{2}, a n}$ : mass of hydrogen in the stack anode [kg].

- $x_{7}=m_{v_{2}, a n}$ : mass of vapour in the stack anode [kg].

The complete set of equations and physical parameters is not included here for space reasons and can be found in (Kunusch et al., 2011).

\section{Control objective and sliding surface}

As already stated, the main objective of the proposed control strategy is the optimization of the energy conversion of the fuel cell, maximizing the net power generated by the system under different load conditions. Considering that the compressor is also driven by the fuel cell (in fact, it can be regarded as a parasitic load), the output net power $\left(P_{n e t}\right)$ can be defined as the electrical power delivered by the stack $\left(P_{s t}=V_{s t} I_{s t}\right)$ minus the electrical power consumed by the compression subsystem $\left(P_{c p}=V_{c p} I_{c p}\right)$. Optimization of the system efficiency can be achieved by regulating the air mass flow entering to the stack cathode at different load conditions.

Accomplishing such optimal comburent flow is equivalent to maintaining the cathode line oxygen stoichiometry (or oxygen excess ratio) in an optimal value. This becomes evident from Figure 3. The optimum value of $\lambda_{o_{2}}$ can be experimentally determined from a thorough off-line analysis of the open loop system, considering changes in the current demanded to the stack and a wide set of stoichiometry values.

The oxygen stoichiometry is defined as:

$$
\lambda_{o_{2}}=\frac{W_{o_{2}, \text { in }}}{W_{o_{2}, \text { react }}}
$$

where $W_{o_{2}, \text { in }}$ is the oxygen partial flow in the cathode, which depends on the air flow released by the compressor $W_{c p}$ and the vapour injected by the humidifier. $W_{o_{2}, \text { react }}$ is the oxygen flow consumed in the reaction. It can be directly related to the total stack current $\left(I_{s t}\right)$ :

$$
W_{o_{2}, \text { react }}=G_{o_{2}} \frac{n I_{s t}}{4 F}
$$

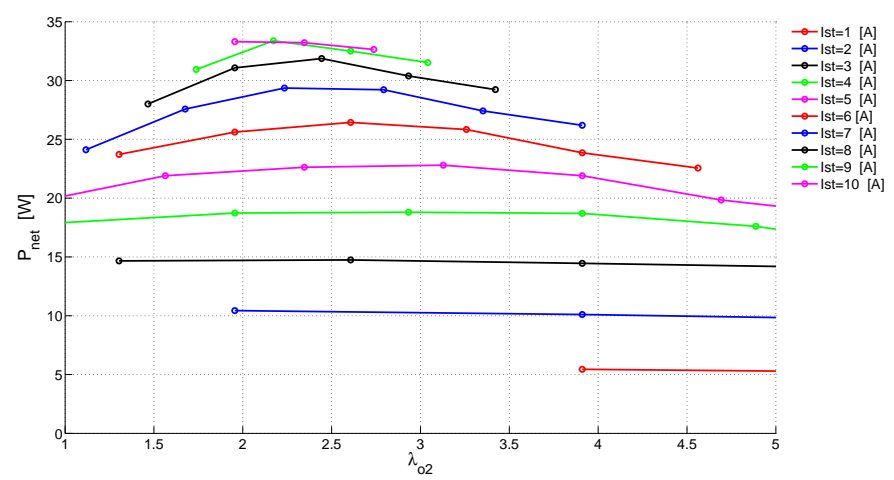

Figure 3: System performance in different load conditions $\left(P_{n e t}\right.$ vs. $\left.\lambda_{o 2}\right)$

$G_{o 2}$ is the molar mass of oxygen, $n$ the total number of cells of the stack and $F$ the Faraday constant.

Once $\lambda_{o_{2}, \text { opt }}$ is determined, the objective of keeping the oxygen excess ratio within optimal values can be achieved controlling the oxygen mass flow $\left(W_{o_{2}, \text { in }}\right)$. It is important to highlight that in the current work the optimal oxygen stoichiometry was determined from an off-line analysis as it is shown in Figure 3. For the current system this optimal operating point ranges from 2 to 3 . In nominal operation, the experimental system is usually set to work at $\lambda_{o_{2}, o p t}=2.3$. Nevertheless, an enhanced approach can be done using on-line extremum seeking algorithms, this is still an open topic where the authors are currently working.

Then, once fixed $\lambda_{o_{2}, \text { opt }}$ the following mass flow reference can be obtained from (1) and (2):

$$
W_{o_{2}, \text { in,ref }}=\lambda_{o_{2}, o p t} M_{o_{2}} \frac{n I_{s t}}{4 F}
$$

where tracking $W_{o_{2}, \text { in, ref }}$ effectively implies $\lambda_{o_{2}}=\lambda_{o_{2}, \text { opt }}$. Nevertheless, due to the fact that $W_{o_{2}, \text { in }}$ is an internal unavailable variable of the system, it is not practical to include it in the control algorithm. This problem can be circumvented by inferring information of $W_{o_{2}}$,in from an accessible variable of the system, such as the air mass flow delivered by the compressor $W_{c p}$. Note that once the humidifier transient is extinguished, the relationship between $W_{c p}$ and $W_{o_{2}, \text { in }}$ remains constant.

In the framework of the sliding mode theory, this control objective can be expressed as follows:

$$
\begin{aligned}
S(x) & =W_{c p}-W_{c p, r e f}= \\
& =B_{00}+B_{10}\left(x_{2} \frac{T_{\text {hum }} R_{a}}{V_{\text {hum }}}+K_{\text {hum }}\right)+ \\
& +B_{20}\left(x_{2} \frac{T_{\text {hum }} R_{a}}{V_{\text {hum }}}+K_{\text {hum }}\right)^{2}+B_{01} x_{I}+ \\
& +B_{11}\left(x_{2} \frac{T_{\text {hum }} R_{a}}{V_{\text {hum }}}+K_{\text {hum }}\right) x_{1}+B_{02} x_{1}^{2}-W_{c p, r e f},
\end{aligned}
$$

where $S$ is the sliding variable that must be steered to zero, $W_{c p, r e f}$ the compressor air mass flow and $W_{c p, r e f}$ is the flow reference. The compressor parameters $B_{00}, B_{01}, B_{10}, B_{11}, B_{02}$ 
and $B_{20}$ can be obtained from (Kunusch et al., 2011), $T_{\text {hum }}$ is the humidifier temperature, $V_{\text {hum }}$ is the humidifier volume, $R_{a}$ the air gas constant and

$$
K_{\text {hum }}=P_{\text {sat }}\left(T_{\text {hum }}\right) R H_{\text {hum }}-P_{\text {sat }}\left(T_{\text {amb }}\right) R H_{\text {amb }},
$$

being $P_{\text {sat }}\left(T_{\text {hum }}\right)$ the vapour saturation pressure at $T_{\text {hum }}, R H_{\text {hum }}$ the relative humidity of the gas at the humidifier output, $P_{\text {sat }}\left(T_{a m b}\right)$ the vapour saturation pressure at ambient temperature and $R H_{\text {hum }}$ the relative humidity of ambient air. All these variables are considered constant.

The expression of $W_{c p, r e f}$ can be readily obtained from the air mass flow reference. Given that the molar fraction of oxygen in the air $\left(\chi_{o 2}\right)$ is known, the desired mass flow of dry air can be directly computed from:

$$
W_{\text {dry air,ref }}=\frac{1}{\chi_{o 2}} W_{o_{2}, i n_{r e f}}=\frac{1}{\chi_{o 2}} \lambda_{o_{2}, o p t} M_{o_{2}} \frac{n I_{s t}}{4 F} .
$$

Then, taking into account the relative humidity of the air $\left(\Omega_{\text {atm }}\right)$, the final expression of the air mass reference results:

$$
W_{c p, r e f}=\left(1+\Omega_{a t m}\right) \frac{1}{\chi_{o 2}} \lambda_{o 2, o p t} M_{o 2} \frac{n I_{s t}}{4 F} .
$$

Note that for stable ambient conditions, the reference only depends on a single measurable variable, i.e. the stack current $I_{s t}$.

\section{Design and analysis of PEMFC-STA controller}

It has been established in Section 1 that SOSM techniques present attractive characteristics that well suit the PEMFC breathing control requirements. Together with the general features of robustness, enhanced accuracy, finite time convergence and chattering reduction, in particular, the generation of continuous control action signals avoid output power quality deterioration and the inconvenience of discontinuous voltage directly applied to the compressor input.

A battery of SOSM algorithms can be found in the literature, each one of them with its distinctive features. In this work, the Super Twisting has been chosen to evaluate the viability of the SOSM approach to this fuel cell system. This is because this algorithm is specially suited for relative degree one plants and do not require information about the sign of the surface derivative. To this aim, the controller has been designed using the detailed model description given in (Kunusch et al., 2011)) and has been assessed by thorough simulation tests and experimentally. To obtain the controller gains, an initial design procedure, must be followed. To begin with, the first and second time derivatives of the sliding variable (5) have to be computed. They can be expressed as:

$$
\dot{S}=\frac{\partial}{\partial t} S(t, x)+\frac{\partial}{\partial x} S(t, x) \cdot(F(x)+G u),
$$

$$
\begin{gathered}
\ddot{S}=\frac{\partial}{\partial t} \dot{S}(t, x, u)+\frac{\partial}{\partial x} \dot{S}(t, x, u) .(F(x)+G u)+ \\
+\frac{\partial}{\partial u} \dot{S}(t, x, u) \cdot \dot{u}(t)=\varphi(t, x, u)+\gamma(t, x, u) \dot{u}(t)
\end{gathered}
$$

where $\varphi(t, x, u)$ and $\gamma(t, x, u)$ for the PEMFC system are smooth functions, that have to be bounded as follows:

$$
\begin{gathered}
0<\Gamma_{m} \leq \gamma(t, x, u) \leq \Gamma_{M} \\
|\varphi(t, x, u)| \leq \Phi .
\end{gathered}
$$

For the PEMFC under study, the bounding values were computed by means of a numerical study of the nonlinear system and refined through a physical analysis. Additionally, uncertainties were included in representative parameters such as the motor inertia, torque friction, humidifier volume and cathode air constant. The following values were obtained:

$$
\Phi=2.310^{-5} ; \quad \Gamma_{m}=0,002 ; \quad \Gamma_{M}=0,0083
$$

Once the bounds have been determined, the stabilization problem of system (7) with input-output dynamics (8) can be solved through the solutions of the following equivalent differential inclusion by applying SOSM:

$$
\ddot{S} \in[-\Phi, \Phi]+\left[\Gamma_{m}, \Gamma_{M}\right] \dot{u} .
$$

Then, the gains of the STA are calculated from $\Phi, \Gamma_{m}$ and $\Gamma_{M}$ guaranteeing that, once the system is steered to the region where they hold, the trajectories do not escape and converge to $S=\dot{S}=0$ in $t<\infty$.

The implemented Super Twisting algorithm is insensitive respect to Lipschitz perturbations, while the control law is continuous.

\subsection{Super Twisting Algorithm}

This algorithm is intended to systems with relative degree 1, this is the case of the presented PEM fuel cell system. One interesting feature of the STA is that during on-line operation, it does not require information of $\dot{S}$. The trajectories converge to the origin of the sliding plane turning around in a typical way. The control law comprises two terms. One is the integral of a discontinuous control action and, the other, is a continuous function of $S$, contributing only during the reaching phase (Levant, 1993):

$$
\begin{gathered}
u(t)=u_{1}+u_{2} \\
\dot{u}_{1}=-\gamma \operatorname{sign}(S) \\
u_{2}=-\lambda|S|^{1 / 2} \operatorname{sign}(S),
\end{gathered}
$$

where $\gamma$ and $\lambda$ are design parameters that can be first derived from the corresponding sufficient conditions for finite time convergence of the algorithm (Levant, 1993):

$$
\begin{aligned}
& \gamma>\frac{\Phi}{\Gamma_{m}} \\
& \lambda>\sqrt{\frac{2}{\Gamma_{m}^{2}} \frac{\left(\Gamma_{m} \gamma+\Phi\right)^{2}}{\left(\Gamma_{m} \gamma-\Phi\right)}} .
\end{aligned}
$$


To begin with, the following set of controller parameters was selected in order fulfil and obtain a good trade-off between dynamic performance and chattering attenuation in the experimental set-up:

$$
\lambda=20 ; \gamma=0,08
$$

\subsection{Lyapunov stability analysis and convergence time estima- tion}

Lyapunov functions as basic tools for analysis and design in modern control theory, can provide a powerful methodology to analyse stability issues in Second Order Sliding Modes. In this section, a Lyapunov based analysis is presented in order to check the system stability, analyse its perturbations and give an upper bound of the algorithm convergence time.

In this context, the first Lyapunov function for the Super Twisting Algorithm was first reported in (Moreno and Osorio, 2008) by J.A. Moreno and co-workers. In such work, a strong and robust Lyapunov function is introduced, but its handling is cumbersome. Recent advances in the formalization of the generalised Super Twisting algorithm (a wider class of algorithms that includes the Super Twisting algorithm of fixed gains), have provided another approach to obtain quadratic Lyapunov functions that is also useful to estimate the algorithm convergence time and robustness properties.

For the PEM fuel cell system under study and considering $\frac{\partial}{\partial t} S(t, x)=0$, the equation (7) under the effect of control (13) can be presented as follows:

$$
\begin{aligned}
& \dot{S}=\frac{\partial}{\partial x} S(x)\left[F(x)+G\left(-\lambda \Phi_{1}(S)+u_{1}\right)\right] \\
& \dot{u}_{1}=-2 \gamma \Phi_{2}(S),
\end{aligned}
$$

with

$$
\begin{aligned}
& \Phi_{1}(S)=|S|^{\frac{1}{2}} \operatorname{sign}(S), \\
& \Phi_{2}(S)=\frac{1}{2} \operatorname{sign}(S) .
\end{aligned}
$$

Equivalently, a useful coordinate transformation can be considered in order to analyse the problem and size the perturbation that affect the controlled system (16). Taking into account that the sliding variable is given by equation (5), the control objective can be attained as:

$$
x_{2}=h\left(x_{1}, S\right)
$$

where $h\left(x_{1}, S\right)$ is the solution of the implicit equation (5).

After this transformation procedure, the underlying system under Super Twisting control (implicit system) can be expressed as follows:

$$
\begin{aligned}
\dot{x}_{1} & =\left.F_{1}\left(x_{1}, x_{2}\right)\right|_{x_{2}=h\left(x_{1}, S\right)}+G u= \\
& =\rho\left(x_{1}, S\right)+G\left(-\lambda \Phi_{1}(S)+u_{1}\right) .
\end{aligned}
$$

where $\rho\left(x_{1}, S\right)$ can be considered as a bounded disturbance $\left(\left|\rho\left(x_{1}, S\right)\right|<L\right)$ that affects the control performance. Note that if $\frac{\partial}{\partial t} S(t, x) \neq 0$ but it is bounded, its value can be included in the bound of $L$.

To provide a better description of the perturbations that can be counteracted by the Super Twisting algorithm, the uncertainty/disturbance can always be written as follows (Gonzalez
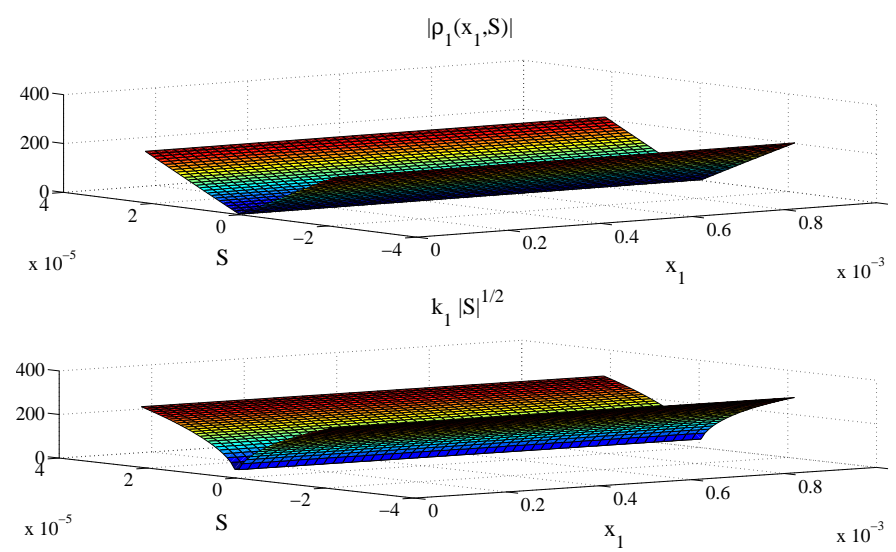

Figure 4: Perturbation analysis of the implicit system

et al., 2012):

$$
\begin{aligned}
\rho\left(x_{1}, S\right) & =\underbrace{\left[\rho\left(x_{1}, S\right)-\rho\left(x_{1}, 0\right)\right]}_{\rho_{1}\left(x_{1}, S\right)}+\underbrace{\rho\left(x_{1}, 0\right)}_{\rho_{2}\left(x_{1}\right)} \\
& =\rho_{1}\left(x_{1}, S\right)+\rho_{2}\left(x_{1}\right),
\end{aligned}
$$

where $\rho_{1}\left(x_{1}, S\right)=0$ when $S=0$. In accordance with (Moreno and Osorio, 2012), the Super Twisting controller is robust to general perturbations $\rho\left(x_{1}, S\right)$ satisfying the following conditions:

$$
\begin{aligned}
& \left|\rho_{1}\left(x_{1}, S\right)\right| \leq k_{1}|S|^{1 / 2} \\
& \left|\frac{\partial}{\partial t} \rho_{2}\left(x_{1}\right)\right| \leq k_{2},
\end{aligned}
$$

with

$$
k_{1}>0, k_{2}>0 \text {. }
$$

A detailed stabilty proof of the STA under pertubations fulfiling (20)-(21) can be found in (Moreno and Osorio, 2012).

For the considered problem, these perturbation terms can be bounded in the entire range of operating conditions of the PEM fuel cell system, as it is shown in Figure 4. Moreover, constants of inequalities (21) can be founded $\left(k_{1}=0.8 \times 10^{3}, k_{2}=4 \times 10^{2}\right)$.

As stated in (Moreno, 2011; Moreno and Osorio, 2012), this a strong requirement in order to ensure the complete rejection of the disturbance $\rho\left(x_{1}, S\right)$ by the Super Twisting controller. This allows to develop a general stability proof of the Super Twisting algorithm subject to the general class of disturbances in equation (16) bounded as (21). The proof is based on the following family of quadratic Lyapunov functions:

$$
\begin{aligned}
& V\left(\zeta, u_{1}\right)=\zeta^{T} P \zeta, \\
& \zeta=\left[|S|^{\frac{1}{2}} \operatorname{sign}(S), u_{1}\right]^{T},
\end{aligned}
$$

where matrix $P=P^{T}>0$ is a symmetric and positive definite solution of the following linear matrix inequality (LMI) with some constant $\epsilon>0$ :

$$
\left[\begin{array}{cc}
A^{T} P+P A+\epsilon P+R & P B \\
B^{T} & -\Theta
\end{array}\right] \leq 0,
$$


being $A$ the Hurwitz matrix of the controlled system (16)

$$
A=\left[\begin{array}{ll}
-\frac{\lambda}{G} & 1 \\
-\frac{\gamma}{G} & 0
\end{array}\right]=\left[\begin{array}{cc}
-1.3097 \times 10^{4} & 1 \\
-52,38 & 0
\end{array}\right],
$$

$Q$ is an arbitrary symmetric and positive definite matrix $Q=$ $Q^{T}>0, B=\left[\begin{array}{ll}1 & 0\end{array}\right]^{T}$ and $G=15.27 \times 10^{-4}$. The matrices $R$ and $\Theta$ take into account the perturbation bounds of the stated problem and can be considered as parameters for control design.

Then, the function (22) is a global strong Lyapunov function for the system (16-17). From (Dávila et al., 2009) it can be stated that the selection of $Q=I$ (identity matrix) is the best choice to estimate the minimal time in the family of Lyapunov functions without perturbations. Using this selection of $Q$ for the system under study, the matrix $P=P^{T}>0$ from (23) results:

$$
P=\left[\begin{array}{cc}
0.0003 & -0.0162 \\
-0.0162 & 4.0560
\end{array}\right],
$$

with $\epsilon=1.8 \times 10^{-15}$.

In (Moreno, 2011; Moreno and Osorio, 2012) it is given the proof that the system trajectories under Super Twisting control starting at $S_{0}=[S(0), \dot{S}(0)]$, to the origin in finite time when the perturbation $\rho\left(x_{1}, S\right)$ of equation (16) is bounded by (21).

From the Lyapunov function (22) it is also possible to obtain an estimate for the convergence time. From (Dávila et al., 2009), it can be stated that being $\frac{\lambda}{G}>0$ and $\frac{\gamma}{G}>0$, a trajectory of the system starting at $S_{0}$ converge to the origin at most after a time $T\left(S_{0}\right)$ :

$$
T\left(S_{0}\right)=\frac{2}{\gamma_{1}\left(Q, \frac{\lambda}{G}\right)} V^{1 / 2}\left(S_{0}\right),
$$

with

$$
\gamma_{1}\left(Q, \frac{\lambda}{G}\right)=\left(\frac{\lambda}{G}\right)^{2} \frac{1}{2} \frac{\lambda_{\min }\{Q\} \lambda_{\min }^{1 / 2}\{P\}}{\lambda_{\max }\{P\}}
$$

In conclusion, the presented approach show the stability of the Super Twisting algorithm when controlling the fuel cell oxygen of the presented PEM fuel cell system. Therefore, given certain controller gains $\lambda, \gamma$ and given the perturbation bounds of the system, then the robust finite time stability of the algorithm is assured through a strong Lyapunov function and an upper estimate of the convergence time can be computed. Remark: it is important to highlight that this is a conservative estimation of the convergence time, but it is guaranteed for the entire operation range of the system (Dávila et al., 2009).

\subsection{Feedforward term}

It was previously stated that it is necessary to define an extra control action that steers the sliding variable within a region such that the bounds on the sliding dynamics given in (9-10) are satisfied (Fridman and Levant, 2002). With this purpose, it has been included a feedforward (FF) action $u_{f f}$ based on the stack current, implicitly through the reference $W_{c p, r e f}(6)$. It provides the control effort required to reach the surface neighbourhood where conditions (9-10) hold. Therefore, the implemented control action $\left(u_{i}\right)$ comprises two terms:
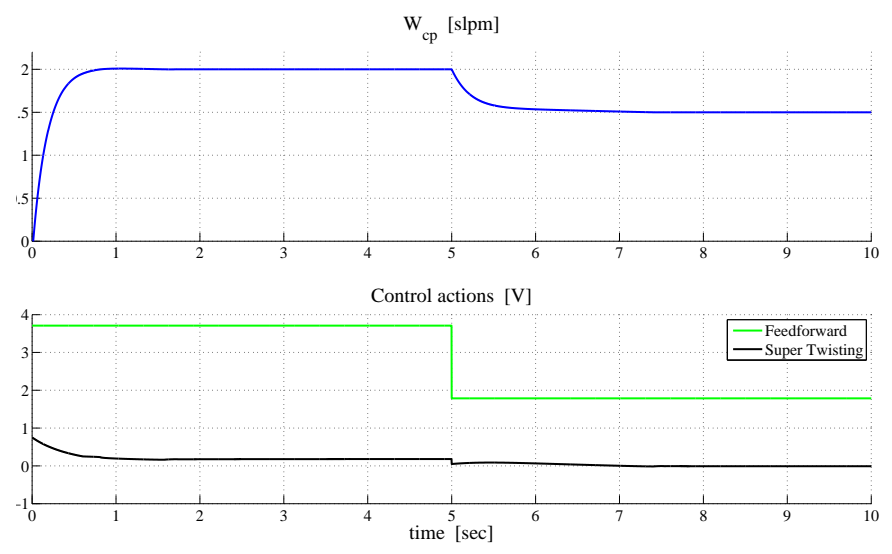

Figure 5: Air flow and control input (simulation results)

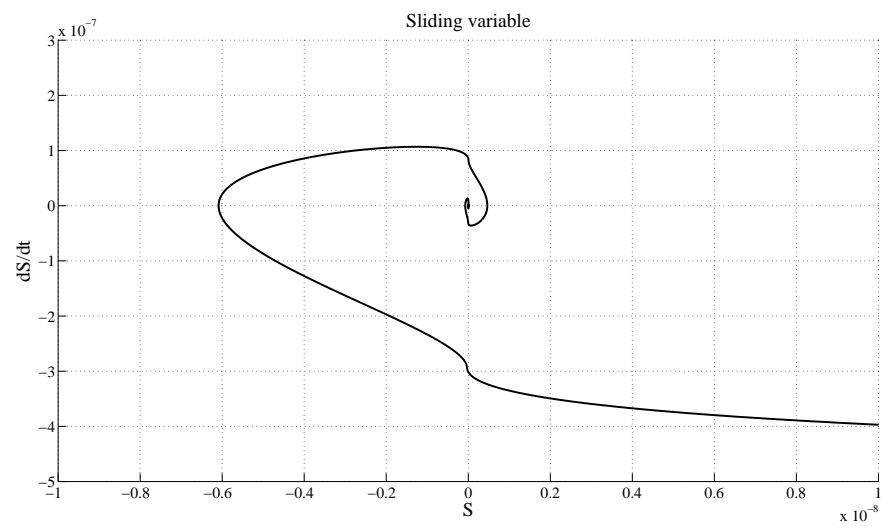

Figure 6: $S$ vs. $\dot{S}$ (simulation results)

$$
u_{i}(t)=u_{f f}+u,
$$

where $u$ corresponds to the SOSM control action particularised above. The expression of $u_{f f}$ is computed via a polynomial obtained from an off-line test covering the entire operation range of the experimental PEMFC system and is given by:

$$
\begin{aligned}
u_{f f} & =0.1014 W_{c p, r e f}^{6}-1.1412 W_{c p, r e f}^{5}+ \\
& +4.8303 W_{c p, r e f}^{4}-9.3370 W_{c p, r e f}^{3}+ \\
& +8.1430 W_{c p, r e f}^{2}-0.6129 W_{c p, r e f}-0.1934
\end{aligned}
$$

The following figures present the simulations results of the controlled system using the algorithm designed above. Figure 5 shows that the Super Twisting controller present a satisfactory dynamic response when controlling the air mass flow. In Figure 6, the typical behaviour that impose the algorithm to the nonlinear system is shown through as $S-\dot{S}$ diagram. It is important to stress that, after an adequate parameters tuning, the controller presents a satisfactory dynamic behaviour, confirming the suitability of the STA for the breathing control of this PEMFC system. 


\section{Experimental results}

The main objective of this section is to present the performance of the proposed SOSM controller, implemented in the fuel cell test station, considering external disturbances and different working conditions.

Among several simulations and experimental tests performed in the fuel cell system, a first approach to solve the real problem was implemented through the designed Super Twisting controller. Considering that the plant has a relative degree one, the Super Twisting algorithm appears as particularly suitable option for the current laboratory implementation. Another implementation advantage of this algorithm is that it does not require information of the sign of $\dot{S}$.

To assess the controller (12-13-30) performance in real operation, in Figure 7 it can be appreciated the performance of the SOSM+FF controller at different load conditions. Comparing Figure 7 and Figure 5, it can be stated that the simulation and experimental results preserve the same dynamic behaviour, showing the reliability, robustness and accuracy of the design methodology.

Furthermore, another representative set of tests was performed in the PEM fuel cell test station, forcing an external perturbation in the cathode line pressure. In these experiments, the control performance was assessed at a fixed control reference, see Figure 8, while a pressure disturbance in the air pressure was incorporated by means of an electronic valve.

It can be noticed that the control objective is satisfactory accomplished during the imposed perturbation. Moreover, when the system is strongly disturbed $(t \simeq 195 \mathrm{~s}$ ), the controller drives again the system trajectories to the sliding surface. This effect is achieved because the stability of the closed loop system is guaranteed given that the differential inclusion (11) is satisfied.

Apart from the presented examples, extensive simulation and experimental analysis have been conducted and, in every case, highly satisfactory results have been obtained using the proposed Super Twisting controller. It is important to empathise that the proposed STA+FF controller showed very good performance for a wide range of operating conditions, proving robustness with respect to external disturbances and model uncertainties.

\section{Conclusions}

After evaluating a second order sliding mode controller solution to globally solve the oxygen stoichiometry problem of a PEMFC generation system, a Super Twisting controller has been developed and implemented in a laboratory test station. Its suitability was successfully verified through extensive computer simulations, based on a previously designed model of the plant especially built for nonlinear control purposes and taking into account external disturbances and uncertainties in the system parameters (Kunusch et al., 2011). Subsequently, highly satisfactory experimental results using the aforementioned approach, confirm the feasibility, simplicity and robustness of the solution. Main advantages of the proposed Super Twisting control for PEMFC systems can be summarized as follows:
- robust stabilization of the oxygen stoichiometry problem avoiding chattering effects;

- enhanced dynamic characteristics;

- robustness to parameter uncertainties and external disturbances;

- guaranteed extended range of operation, in spite of the highly nonlinear nature of plant;

- the control law only depends on two measurable variables, namely the stack current and the compressor air flow, therefore no state observer is required;

- simple controller structure, resulting in low real time computational costs.

The resulting controller is relatively simple to design and tune, only requiring certain measurements of easy and low cost implementation. This represent important issue for fuel cells industrial applications, where the plant instrumentation is critical.

\section{Acknowledgements}

All the experimental tests were performed at the PEM Fuel Cells Laboratory of the Institut de Robòtica i Informàtica Industrial (CSIC-UPC, Barcelona, Spain) and only possible due to its advanced equipment and proficient technical staff. This research has been supported by the Seventh Framework Programme of the European Community through the Marie Curie actions (GA: PCIG09-GA-2011-293876), the CICYT project DPI2011-25649 (MICINN-España), the CSIC JAEDOC Research Programme, Universidad Nacional de La Plata (UNLP), CONICET and CICpBA from Argentina, Universidad Nacional Autonóma de México (UNAM) and projects FONCICyT- 93302, PAPIIT-117211 and CONACyT-132125.

\section{References}

Barbir, F., 2005. PEM fuel cells: theory and practice. Elsevier.

Dávila, A., Moreno, J., Fridman, L., 2009. Optimal lyapunov function selection for reaching time estimation of super twisting algorithm, in: 48th IEEE Conference on Decision and Control, pp. 8405-8410.

Fridman, L., Levant, A., 2002. Sliding Mode Control in Engineering. Marcel Dekker, Inc.. chapter 3 "Higher Order Sliding Modes". pp. 53-101.

García-Gabin, W., Dorado, F., Bordons, C., 2010. Real-time implementation of a sliding mode controller for air supply on a pem fuel cell. Journal of Process Control 20, 325-336.

Gonzalez, T., Moreno, J., Fridman, L., 2012. Analysis of chattering in continuous sliding-mode controllers. Variable Gain Super-Twisting Sliding Mode Control DOI: 10.1109/TAC.2011.2179878.

Gruber, J., Bordons, C., Oliva, A., 2012. Nonlinear MPC for the airflow in a pem fuel cell using a volterra series model. Control Engineering Practice 20, 205217.

Kunusch, C., Puleston, P., Mayosky, M., Husar, A., 2011. Control oriented modelling and experimental validation of a PEMFC generation system. IEEE Transactions on Energy Conversion. 6, 851-861.

Kunusch, C., Puleston, P., Mayosky, M., Riera, J., 2009. Sliding mode strategy for PEM fuel cells stacks breathing control using a Super-Twisting algorithm. IEEE Transactions on Control Systems Technology 17, 167-174. 

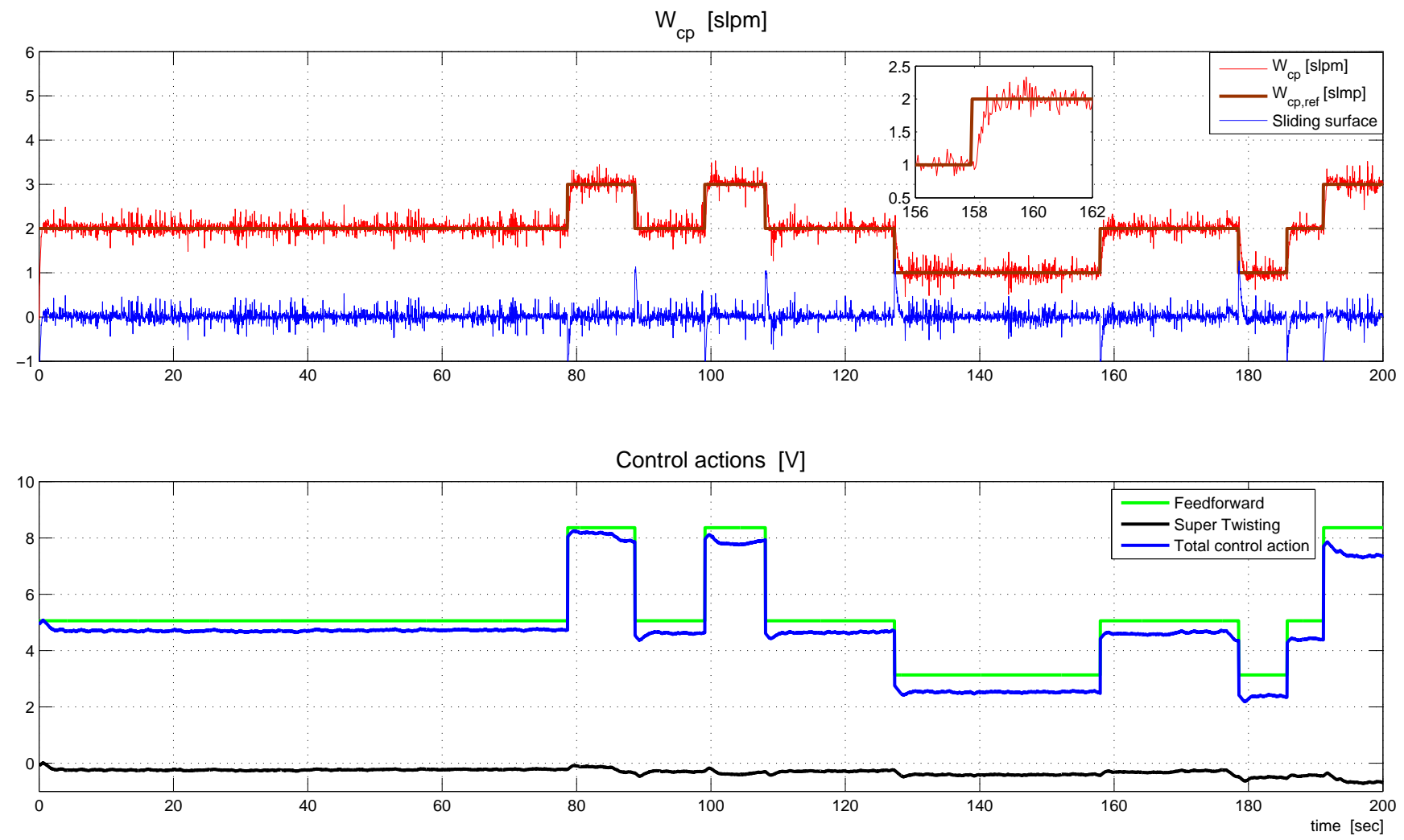

Figure 7: $W_{c p}$ regulation with SOSM+FF controller (experimental results)

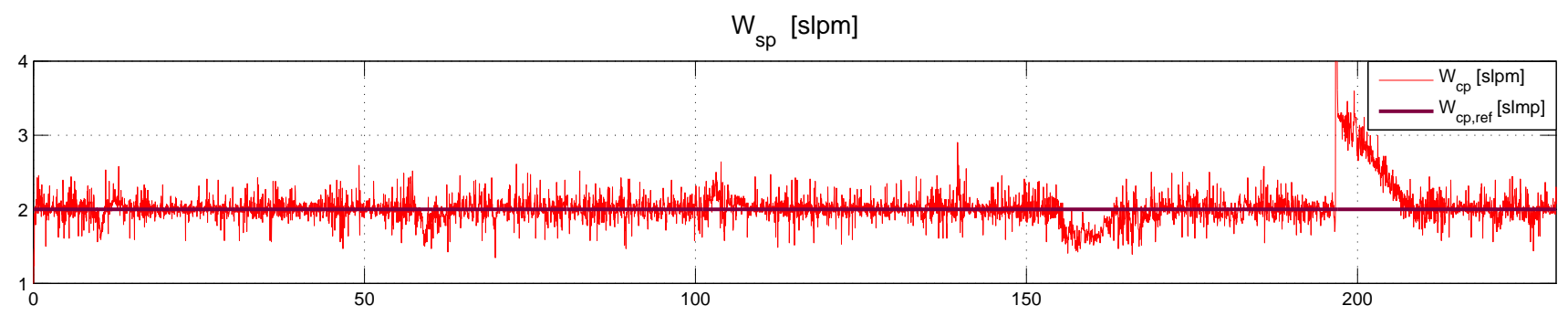

Control actions [V]

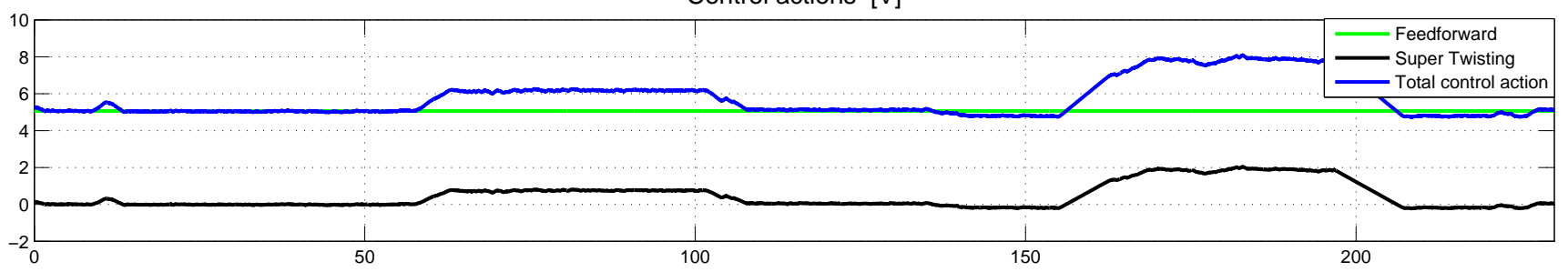

Compressor pressure [bar]

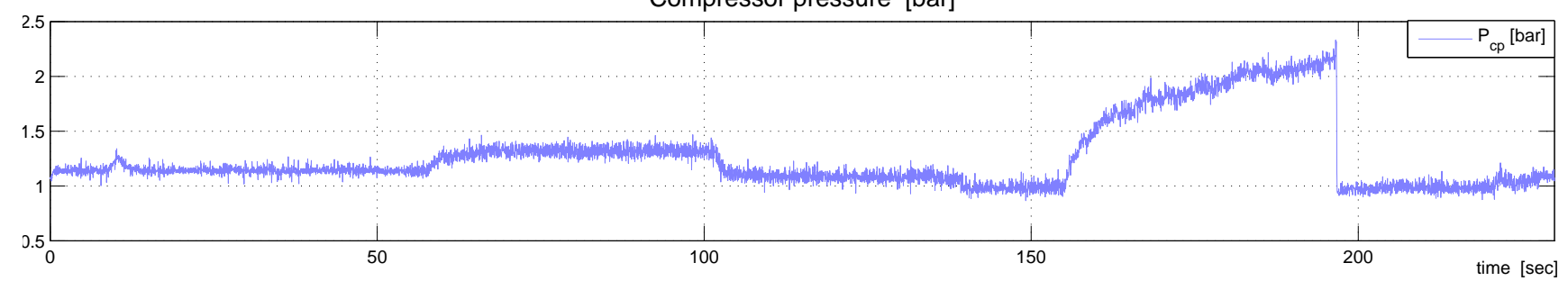

Figure 8: Perturbation test (experimental results) 
Larminie, J., Dicks, A., 2003. Fuel Cell Systems Explained. John Wiley \& Sons Inc. second edition.

Levant, A., 1993. Sliding order and sliding accuracy in sliding mode control. International Journal of Control 58, 1247-1263.

Matraji, I., Laghrouche, S., Wack, M., 2010. Second order sliding mode control for PEM fuel cells, in: 49th IEEE Conference on Decision and Control.

Moreno, J., 2011. Lyapunov Approach for Analysis and Design of Second Order Sliding Mode Algorithms. Springer. chapter 4. pp. 122-150.

Moreno, J., Osorio, M., 2008. A lyapunov approach to second-order sliding mode controllers and observers, in: 47th IEEE Conference on Decision and Control, pp. 2856-2861.

Moreno, J., Osorio, M., 2012. Strict lyapunov functions for the super-twisting algorithm. IEEE Transactions on Automatic Control 57, 1035-1040.

Pukrushpan, J., Stefanopoulou, A., Peng, H., 2004. Control of Fuel Cell Power Systems. Springer.

Talj, R., Hissel, D., Ortega, R., Becherif, M., Hilairet, M., 2010. Experimental validation of a PEM fuel-cell reduced-order model and a moto-compressor higher order sliding-mode control. IEEE Transactions on Industrial Electronics 57, 1906-1913. 